\title{
Mineração, agricultura familiar e saúde coletiva: um estudo de caso na região de Itamarati de Minas-MG
}

I 1 Alen Batista Henriques, ${ }^{2}$ Marcelo Firpo de Souza Porto I

Resumo: O artigo discute, à luz dos paradigmas da ecologia política e da justiça ambiental, os impactos socioambientais e à saúde coletiva resultantes do processo de extração mineral no município de Itamarati de Minas-MG. Os objetivos se encerram na compreensão dos riscos e vulnerabilidades socioambientais produzidos, assim como na apreensão dos conflitos e dos cenários de injustiça ambiental, próprios a essa atividade econômica. Na primeira parte são apresentadas, de forma abreviada, algumas características do atual modelo de exploração mineral e de inserção mundial subordinada de territórios como o do município de Itamarati de Minas. Em seguida, tem lugar uma descrição da área estudada e das fontes e métodos utilizados no trabalho; em seguida, são apresentados os resultados das entrevistas. Percebeu-se que o processo de mineração de bauxita é impactante ao meio ambiente e aos modos de vida da coletividade; do mesmo modo, atua de forma negativa no processo de produção de saúde e doença, estorvando uma situação de promoção de saúde.

> Palavras-chave: saúde coletiva; saúde ambiental; mineração; justiça ambiental.

\author{
1 Faculdade de Educação, \\ Universidade do Estado de \\ Minas Gerais. Itamarati de \\ Minas-MG, Brasil. Endereço \\ eletrônico: alenhenriques@ \\ gmail.com \\ ${ }^{2}$ Escola Nacional de Saúde \\ Pública Sérgio Arouca, \\ Fundação Oswaldo Cruz. Rio \\ de Janeiro-RJ, Brasil. Endereço \\ eletrônico: marcelo.firpo.@ \\ esnsp.fiocruz.br
}


A exploração de recursos minerais deve ser compreendida a partir de uma visão integradora que valorize desde questões materiais e simbólicas, típicas dos territórios, mas que envolva dimensões geográficas e históricas, socioeconômicas e ambientais, ao mesmo tempo norteadas e condicionadas pelos usos dos recursos naturais em associação com as lógicas globais de acumulação capitaneadas pelas grandes empresas. $\mathrm{O}$ concatenamento dessas dimensões permite desvendar e melhor compreender os agravos à saúde coletiva das populações que ocupam os territórios envolvidos em processos como os de mineração.

Minas Gerais é um estado historicamente marcado pela importância econômica das atividades minerárias, berço, a título de exemplo, da antiga Vale do Rio Doce. $\mathrm{Na}$ região da Zona da Mata, a existência de reservas de bauxita, associada à proximidade com os grandes centros econômicos do país, levou à implantação nessa região, no decorrer das duas últimas décadas, de duas plantas de exploração e beneficiamento de bauxita, matéria-prima do alumínio. Como efeito imediato, as populaçōes dos territórios passaram a conviver com a apropriação, por parte das empresas, de recursos naturais como a água e dos usos do solo. Ao mesmo tempo, elas passaram a ser impactadas por mudanças bruscas no ambiente físico e social e nas relações de poder que, por sua vez, interferem diretamente na organização dos espaços vividos pela coletividade (HENRIQUES; PORTO, 2013a).

A lógica de produção imposta verticalmente, característica do atual processo de globalização, tem redimensionado o poder econômico das empresas para além dos limites do território nacional. Tornou-se praxe para as grandes empresas a criação, de forma independente, de suas próprias territorialidades e espacialidades, a busca por mercados de consumo e localizaçôes de unidades produtivas e/ou áreas para exploração de matéria-prima (ZHOURI; LASCHEFSKI, 2010). Nesse processo de integração global, as economias locais são forçadas a convergir suas estruturas produtivas regionais, expondo-se "à pluralidade das formas superiores de capitais forâneos" (BRANDÃO, 2007, p. 76). Cristaliza-se, assim, uma produção territorial e de seus usos, diferenciada e sobretudo estranha às formas tradicionais de ocupação e de sobrevivência das populações neles inseridas. Edificam-se, nesse cenário, condiçōes para o que Harvey (2005) titula de acumulação por espoliação, onde as forças do grande capital são basilares nos processos de produção e de consumo. 
A lógica das grandes empresas é diferente da das populações locais. Para as empresas, a preocupação é sua inserção na economia-mundo com sua política de espacialização, enquanto que as populações locais têm como objeto maior de preocupação, a fixação e a perenidade de seus processos de reprodução. Segundo Coelho, Cunha e Wanderley (2010, p. 279), os múltiplos territórios das empresas são lastros que garantem a "diversificação de fontes de matérias-primas, o aperfeiçoamento da competitividade e, consequentemente, a continuidade da lógica de acumulação". Essa lógica é a garantia de tornar viáveis os investimentos e interesses de se permanecer no mercado global. Para as populações locais, a lógica se restringe à reprodução social e a uma acumulação que permita a continuidade do grupo e a projetos individuais e familiares (COELHO; CUNHA; WANDERLEY, 2010). Desta forma, para as populações locais e para as empresas, os projetos territoriais são distintos.

Ao se (re)produzir novas territorialidades, condicionando os espaços aos interesses econômicos das empresas, são forjadas externalidades socioambientais que são a garantia para a chamada "competitividade" no mercado globalizado (HENRIQUES; PORTO, 2013a; 2013b). Poluição, redução de mananciais e da biodiversidade e o desenvolvimento de conflitos são exemplos de externalidades geradas por empreendimentos como os mineradores.

No caso do alumínio, a produção brasileira passa por um relativo processo de recuperação após uma acentuada queda, resultante da crise internacional. No ano de 2011, a produção de 1.440,4 mil toneladas, além de questões conjunturais, refletiu o encerramento das atividades produtivas nas plantas da Valesul Alumínio, no Rio de Janeiro, e da Novelis do Brasil em Aratu, na Bahia. Em 2012 e 2013, a fabricação nacional voltou a apresentar quedas, alcançando 1.436,4 e 1.304,3 mil toneladas, respectivamente (ABAL, 2014). O crescimento do mercado interno brasileiro tem redimensionado o consumo de alumínio primário, fato que tem obstado as exportações desse produto. Por sua vez, as exportações totais atingiram, em 2012, 3.902 milhões de dólares, o que representou para o país um superávit de 2.547 milhões de dólares (ABAL, 2014).

Conforme se apresenta, a cadeia produtiva do alumínio articula-se ao mercado global, assim como outras cadeias produtivas como as do aço ou do agronegócio. A lógica mundializada de seus produtos, alicerçada no consumo do alumínio primário e/ou da alumina, impõe de forma verticalizada transformações em 
territórios de economia tradicional, ${ }^{1}$ como no caso de Itamarati de Minas. Tais transformaçōes afetam as formas tradicionais de sobrevivência das populações que, à revelia e arredadas das decisões, assistem seus territórios se transformar em plataformas de produção acoplada a uma lógica global.

\section{Área de estudo}

O município de Itamarati de Minas encontra-se localizado na microrregião de Cataguases, integrante da Mesorregião da Zona da Mata de Minas Gerais. Seu território é relativamente pequeno $\left(94,568 \mathrm{Km}^{2}\right)$, fato comum à boa parte dos municípios dessa micro e mesorregião; sua população é de 4.079 habitantes (IBGE, 2010). Itamarati de Minas foi o primeiro município da Zona da Mata de Minas a receber investimentos e implantação de uma planta de mineração de bauxita.

Historicamente, a região da Mata mineira foi um dos últimos bastiōes de proteção das áreas auríferas situadas mais ao centro do atual estado de Minas Gerais. Sua ocupação para efetiva colonização foi retardada, tendo sido iniciada nas décadas iniciais do século XIX. A ocupação da região confundiu-se com a narrativa da substituição da Mata Atlântica por culturas que se alternaram durante o tempo. Conforme citado por Valverde (1958, p. 5) em trabalho pioneiro sobre a região de 1958, "uma das características atuais [década de 1950] da paisagem da Zona da Mata é a falta de matas".

As origens da ocupação do atual município de Itamarati de Minas remontam à segunda metade do século XIX. Várias fazendas foram constituídas a partir do plantio do café, que se desenvolveu substituindo porções da Mata Atlântica (SILVA, 1908). Com a crise da economia cafeeira, parte importante das lavouras foi transformada em áreas de pastagens e, mais tarde, em cultivos de cana-de-açúcar.

O município de Itamarati de Minas foi emancipado politicamente em 1963, desmembrando-se do vizinho município de Cataguases. A base econômica do município é a agricultura familiar, baseada na pequena propriedade, onde se praticam uma pequena policultura e a criação de gado leiteiro. As características fundiárias atuais do município não sofreram profundas transformaçōes, permanecendo semelhante à descrita por Valverde (1958) na década de 1950, fator que, segundo o autor, diferia de outras regiōes vizinhas, onde predominavam os 
latifúndios. A produção atual é comercializada em municípios vizinhos, como no

caso do café e das hortaliças e do leite, encaminhado para cooperativas e laticínios.

\section{Fontes e métodos}

A pesquisa foi aprovada pelo Conselho de Ética da Escola Nacional de Saúde Pública (ENSP/FIOCRUZ), parecer no 141/11, de acordo com a Resolução no 196/1996, do Conselho Nacional em Saúde (BRASIL, 1996).

$\mathrm{O}$ estudo incorporou uma abordagem metodológica qualitativa, na qual se buscou obter informações primárias que permitissem descortinar os acontecimentos que tenham levado ao surgimento e desdobramentos da produção de cenários de conflitos e injustiça ambiental nas áreas rurais do município de Itamarati de Minas, a partir do início do processo de extração de bauxita. Foram realizadas entrevistas junto aos produtores rurais do município e, junto a elas, articularam-se fontes secundárias como as produzidas pelo Instituto Brasileiro de Geografia e Estatística (IBGE).

As residências onde foram realizadas entrevistadas são ocupadas por aproximadamente três pessoas, e a média de idade dos entrevistados girou em torno dos 50 anos, sendo a renda média familiar em torno de um salário mínimo. Em relação à escolaridade dos entrevistados, a maioria possui apenas o ensino fundamental incompleto. Os mais jovens já frequentaram e/ou frequentam o ensino médio, mas o ensino superior ainda parece ser uma realidade distante das famílias. Dos entrevistados, apenas dois proprietários são graduados e ambos têm em comum o fato de serem de fora do município e de terem adquirido as propriedades há pouco tempo.

Os instrumentos utilizados foram entrevistas semiestruturadas, conversas informais e relatos de histórias orais. Foram entrevistadas 40 pessoas, totalizando cerca $15 \%$ do total de residências rurais do município de Itamarati de Minas, buscando compreender como a população local interage historicamente com o território e sua percepção com o empreendimento minerário, assim como o processo de produção de saúde e doença. A mineração não ocorre em toda a área rural do município; com isso, como critério, procurou-se privilegiar as áreas rurais que, de forma direta ou indireta, estão ligadas à mineração, nesse caso as comunidades conhecidas como Fortaleza, São Lourenço e Caramonos. A população residente nas 40 residências visitadas e entrevistadas totalizaram 115 
pessoas, número que corresponde a aproximadamente $13 \%$ de toda a população rural do município. $\mathrm{O}$ processo de seleção das residências para as entrevistas ocorreu de forma aleatória. $\mathrm{O}$ acesso às residências foi feito após uma visita exploratória, em que foram verificadas suas localizações e a relação destas com a mineração (proximidade da estrada ou das minas). As casas foram visitadas e não houve resistência por parte dos moradores. Após o esclarecimento sobre o objeto da pesquisa, a relação com os entrevistados ocorreu de forma tranquila. Todos os entrevistados assinaram o termo de consentimento, concordando com a participação na pesquisa. As falas dos participantes, ao longo do texto, foram identificadas com a letra "A" e "Aa" (agricultor (a)), seguido de um número correspondente à idade do entrevistado.

O questionário continha questôes demográficas como número de filhos, de pessoas que ocupam o domicílio, idade etc.; temas relacionados à estrutura familiar e residencial como: trajetória familiar e posse da terra; histórico da produção agrícola na propriedade; atividades produtivas atuais, inserção na cadeia produtiva e relações de trabalho. Os temas envolviam os processos de vulnerabilidade ambiental e de saúde, como: danos ambientais relacionados à extração/transporte da bauxita e situações de injustiça ambiental; e a articulação entre a produção de bauxita e o processo de produção de saúde e doença.

Não foi possível uma aproximação com entidades ou órgãos representativos da região. Não existem no município instituições organizadas que representem e defendam os interesses da população rural. O município possui um escritório da EMATER e uma Secretaria Municipal de Agricultura e Turismo. O serviço de extensão rural da EMATER trabalha de forma articulada à secretaria municipal, mas as atividades desenvolvidas são restritas a pequenos incentivos, como venda de adubo e fornecimento de mudas de eucalipto.

\section{Extração de bauxita e produção de riquezas}

O Produto Interno Bruto (PIB) do município de Itamarati de Minas, em 2010, foi de $\mathrm{R} \$ 84$ milhôes. A cidade foi a segunda do Brasil que mais subiu no ranking, passando da posição de 4.577 para a de 2.958 . A extração de bauxita no município foi a atividade econômica que mais contribuiu para o crescimento. ${ }^{2}$

Os dados divulgados pelo IBGE (2010) são reveladores do crescimento desproporcional do PIB de municípios pequenos e mineradores como os de 
Itamarati de Minas. Entretanto, esses números desconsideram as externalidades ambientais do processo produtivo que afetam o ambiente e as populações que ocupam esses territórios. As compensações financeiras ficam aquém e não são suficientes para a recuperação de áreas antes produtivas e/ou, de problemas como o assoreamento e a redução dos cursos de água, fundamentais para as atividades econômicas tradicionais, como a pequena agricultura e a criação de animais.

$\mathrm{O}$ aumento da arrecadação municipal não acarretou melhorias sociais e qualidade vida e de saúde da população, enquanto a receita líquida per capita saltou de R \$ 1.677,48 (a maior da microrregião da Cataguases) no ano 2000 para $\mathrm{R} \$ 1.999,82$ em 2010; o percentual de crianças nascidas abaixo do peso ainda é de $4,1 \%$, e a taxa de analfabetismo acima dos 15 anos é próxima dos $8 \%$ (FJP, 2013). O crescimento econômico se pauta pela produção assimétrica de riquezas no município - se a renda per capita avançou de R \$391,75 nos anos 2000 para R\$ 569,45 em 2010, nesse último ano, mais de 41\% das crianças do município se encontravam em situação domiciliar de baixa renda ( $<1 / 2$ salário mínimo). A razão de renda ${ }^{3}$ baixou de 11,14 para 7,44 no mesmo período, redução menor do que municípios vizinhos onde a economia não é dependente da mineração, como no caso de Itamarati de Minas (DATASUS, 2013).

O discurso da ecoeficiência é alardeado pela empresa representante do grande capital, e somente nos anos de 2010 e 2011 foram investidos R \$ 343,20 milhões reais na chamada "governança ambiental" (VM, 2013). Políticas que se escondem sob a bandeira da chamada responsabilidade social como a manutenção de ONGs em favor das comunidades das regiões onde estão presentes (VM, 2013), cooptam de forma não democrática o poder político municipal, que se vê beneficiado pelo incremento das receitas municipais - $\mathrm{R} \$ 2.917 .592,26$ de compensação financeira pela extração da bauxita, entre os anos de 2001 a 2010 (FJP, 2013) -, robustecendo deste modo, a falta de participação popular nos destinos de seu território.

\section{Impactos ambientais e características socioambientais do território}

A produção da bauxita é extremamente impactante ao meio ambiente. $\mathrm{O}$ relevo da região da Zona da Mata é caracterizado pela ocorrência de morros e serras e a ocorrência da bauxita se dá nas partes elevadas, em boa parte coberta 
por vegetação típica da Mata Atlântica. O mineral é retirado com escavadeiras e transportado por caminhões através de íngremes e perigosas estradas construídas de forma exclusiva para esse fim. Em seguida, o mineral passa por um processo de beneficiamento, onde é lavado e triturado.

A relação entre a mineradora e os proprietários rurais ocorre essencialmente nos momentos de negociação. Os agricultores são procurados pela empresa e negociam um valor específico de indenização pela extração da bauxita na propriedade. Conforme relato dos agricultores, a indenização é estipulada pela empresa e os mesmos não possuem conhecimento técnico que permita avaliar o valor real da bauxita a ser explorada. As condições socioeconômicas dos agricultores os levam na maioria dos casos a aceitar os valores estipulados pela mineradora.

O processo de mineração é itinerante, ou seja, é realizado de forma simultânea em duas ou mais minas em locais diferentes e temporários. Para efeito de estudo, essas áreas foram divididas em três comunidades já existentes, de modo informal, no município: Fortaleza, São Lourenço e Caramonos. Conforme mencionado, o processo de mineração de bauxita não ocorre em todo o município. A extração e transporte da bauxita se concentraram nas três comunidades supracitadas, fato que justifica a seleção das mesmas. Atualmente, a mineração está limitada à comunidade rural conhecida como Caramonos, que ocupa uma área serrana com altitudes relativamente elevadas para a região, que favorecem o cultivo de café, legumes e verduras.

No Brasil, $84,4 \%$ das propriedades rurais são familiares. De acordo com o censo agropecuário de 2006 (IBGE, 2006), cerca de 70\% das propriedades rurais do município são assim. As entrevistas realizadas com a população confirmaram essa situação, revelando um percentual de $87,5 \%$. A população possui fortes vínculos com o território, com valores culturais que extrapolam a simples monetarização do valor das terras. Cerca de $60 \%$ das famílias entrevistadas adquiriram suas propriedades via herança e mais de $20 \%$ são proprietários há mais de 25 anos, dados que fortalecem seu vínculo com o território. As relações de trabalho da população rural do município têm como característica laboral o trabalho familiar. As formas de trabalho, sejam elas ligadas à agricultura ou pecuária, são majoritariamente ligadas ao trabalho familiar, onde filhos e pessoas com laços de parentesco realizam os afazeres, sem a existência da mão-de-obra 
assalariada. Chama a atenção, nessa forma de organização territorial, a existência de sólidos vínculos solidários permeados por uma relação social horizontal.

A distribuição fundiária do município de Itamarati de Minas baseia-se na produção familiar, conforme informações dos censos agropecuários de 1996 e 2006. A importância dessa economia pode ser mensurada pelo número de residentes nas áreas rurais - 869 pessoas (IBGE, 2010) -, o que corresponde a mais de $21 \%$ da população municipal; destas, 723 pessoas estavam ocupadas em atividades ligadas à agropecuária, número que representa 35\% da população economicamente ativa (IBGE, 2010). Apesar de relativamente pequeno, em 2010 (IBGE), foram identificadas 150 hectares plantados com café, 275 com cana-de-açúcar, 120 com feijão e 100 com milho. A população que ocupava 284 domicílios auferia uma renda média anual de $\mathrm{R} \$ 423,00$; e o PIB agropecuário foi calculado em R\$3.950.000,00.

As famílias entrevistadas concordaram que no passado as condições de vida e sobrevivência eram mais difíceis. Não havia acesso a serviços como "energia elétrica, as estradas eram ruins, havia muita pobreza" (A, 69). O acesso a esses serviços e a melhoria das condições gerais do país são os argumentos que sustentaram, na visão dos agricultores, esse progresso. As opções de trabalho eram menores e os filhos não podiam continuar os estudos, devido à distância e a ausência de serviços de transporte. Estudo "era coisa de rico" (Aa, 65). Relataram ainda, nas entrevistas, uma transformação na produção agropecuária. No passado, cultivavam-se mais café, fumo e gêneros alimentícios do que no presente.

O trabalho familiar na roça é bastante pesado e extenuante. A falta de incentivo e apoio por parte de órgãos oficiais também é percebida a partir das entrevistas. Esses são os fatores preponderantes quando se discute a intenção de pensar o futuro das propriedades a partir da perspectiva da continuidade dos filhos na lida. Metade dos entrevistados não avista ou não deseja que seus filhos continuem trabalhando nas propriedades. Justificativas como "quero que meu filho estude" (A, 41) e "o trabalho na roça é muito pesado, quero um futuro melhor para meu filho" (A, 34) são comuns entre as famílias que não desejam que seus filhos permaneçam nas propriedades.

Por sua vez, metade das famílias almeja que seus filhos continuem nas propriedades rurais. As famílias reconhecem as dificuldades, mas apostam no 
futuro reafirmando identidade com o território e com as formas tradicionais de sobrevivência. Como justificativas, apontam as dificuldades de adaptação nas cidades e o custo de vida: "na roça a gente planta de tudo, tem água à vontade...” (A, 49).

\section{Processo de produção de vulnerabilidade socioambiental e de saúde}

Conforme descrito acima, o processo de extração e exploração da bauxita é demasiado impactante para o ambiente. As populações que historicamente habitam os territórios explorados são as que mais sentem os impactos. Se a empresa monopoliza os lucros auferidos com exploração da bauxita, os danos ambientais são distribuídos entre as famílias que tradicionalmente utilizam a terra, sobrevivendo da agricultura e da pecuária. Os impactos ambientais inerentes ao processo produtivo podem ser separados, a priori, naqueles produzidos na exploração da bauxita e aqueles gerados a partir de seu transporte.

Os impactos ligados à extração do minério se associam à retirada de matas e da vegetação original do topo de morros. O resultado é que, mesmo com a adoção, por parte da empresa, de medidas mitigadoras, ocorre sensível redução das águas que são usadas pelas famílias desses territórios. Como medidas chamadas de mitigadoras, a empresa adota um conjunto de expedientes supostamente capazes de solucionar os impactos ambientais produzidos durante a extração da bauxita. A parte fértil do solo é retirada, para posteriormente ser devolvida; valas são construídas para reter as águas pluviais nas partes íngremes; após o esgotamento da mina, ocorre o replantio de vegetação que deveria ser original. Contudo, observa-se nessas áreas a predominância de braquiária e eucalipto. Conforme as entrevistas, os assoreamentos, em períodos chuvosos, são constantes e muitas vezes vêm acompanhados pela poluição das águas que servem para uso diário, como a cocção de alimentos e a higiene, para criação de peixes etc. São comuns depoimentos do tipo: "tem época em que ficamos sem água por mais de uma semana e quando chega nem dá pra cozinhar de tão suja” (A, 67); ou "a água está suja de barro, quando chove a situação piora. Essa situação teve início a partir do começo da mineração na região" (Aa, 51); "a água sujou e não limpa mais" (A, 37). Os problemas relacionados à piora da qualidade e/ou diminuição das águas 
são comuns entre as famílias entrevistadas, o que poderia configurar uma situação

de injustiça ambiental vivida pelos proprietários e moradores dos territórios.

Durante o transporte do minério até a planta de beneficiamento, onde o mesmo é lavado e triturado, e depois até o embarcadouro, situado a cerca de 30 quilômetros, são produzidos difusos impactos ambientais que afetam diretamente as populações residentes ao longo das estradas. Os impactos narrados dizem respeito a questões que expõem de forma aguda as situações de vulnerabilidade socioeconômica e de saúde dessas famílias. Tais condiçôes atuam, sobremaneira, como determinantes no processo de produção de saúde e doença da população que ocupa o território.

A principal queixa da população rural é feita em relação ao excesso de poeira produzida pelo tráfego de caminhões pesados, que transportam o minério diuturnamente. A poeira cobre de tom alaranjado toda a vegetação próxima às estradas e afeta o cultivo de pequenos produtores rurais, impedindo, por exemplo, o cultivo de verduras e legumes. A poeira, provavelmente, está entre as principais externalidades ambientais produzidas pela mineração que afetam de forma indiscriminada todo o território e não apenas as áreas mineradas. Famílias que residem a quilômetros de distância são tão afetadas quanto as que têm suas propriedades cortadas pelas vias de transporte. Do ponto de vista econômico, ouvem-se relatos como: "não posso mais plantar cana para produzir açúcar, por causa da poeira, não consigo adequar às exigências sanitárias" (A, 64); ou, de forma mais crítica de outro produtor: "vou criar vaca e vender leite de poeira" (A, 54). Se a poeira afeta as culturas que margeiam as estradas, o mesmo não é diferente em relação às residências das famílias: "a gente não pode nem colocar a roupa no varal para secar, porque a poeira não deixa” (Aa, 38).

$\mathrm{O}$ transporte da bauxita traz ainda outras questões, não menos importantes, como o risco de acidentes e de atropelamentos, infligido à população local. As famílias se vêm obrigadas a compartilhar, todos os dias, os exíguos e apertados espaços de suas vias usados para o trabalho, para levar os filhos à escola etc., com caminhões carregados com 30 toneladas de minério a velocidades, muitas vezes, acima do permitido. O transporte é feito por empresas terceirizadas e foge ao escopo deste trabalho analisar as condiçôes laborais e de saúde desses trabalhadores. Todavia, a busca pela maximização do lucro vem apoiada pelas 
1372 formas flexíveis de acumulação que têm sido responsáveis pela precarização das condições de trabalho (ANTUNES, 2011). No caso dos motoristas, estes recebem de suas empresas por produtividade, uma forma de ganho salarial pareada ao incremento dos riscos impostos aos trabalhadores. O resultado dessa lógica perversa é o aumento dos riscos de acidentes e de potencialização do processo de vulnerabilização de famílias que vivem e dependem das vias para sobreviver, mesmo que essas não tenham relação alguma com a indústria minerária. $\mathrm{O}$ desabafo de um pequeno proprietário traduz de forma objetiva essa realidade: "os caminhoneiros dirigem como motoboys no Rio de Janeiro" (A, 54).

Outro aspecto envolvendo o transporte da bauxita nas áreas rurais é a poluição sonora. Em determinados períodos, o transporte é realizado à noite e o barulho dos caminhões é contestado pelas famílias: "além do perigo da estrada, a noite é difícil descansar, os caminhões rodam a noite inteira, é difícil até ver televisão" (A, 54).

A poeira é também responsável por problemas de saúde que são narrados de forma incisiva pelas famílias entrevistadas. As doenças respiratórias são as mais recorrentes, com destaque para gripes, alergias, bronquites, sinusites e asmas, queixas comuns dos entrevistados; mas há casos de complicações como de pneumonias e de relatos de internação. Hábitos da rotina dos agricultores são alterados devido à poeira: "tive que parar de andar de bicicleta; passei a ter um chiado no peito e uma tosse que não sara" (A, 64). Os serviços de saúde oferecidos à população são do próprio município. Nas comunidades de São Lourenço e dos Caramonos, existem Unidades Básicas de Saúde, sendo que a primeira se encontra desativada, enquanto que a comunidade de Fortaleza é atendida na sede do município. As três comunidades são cobertas pelo Programa de Saúde da Família, mas a qualidade dos serviços dessa cobertura deixa a desejar, revelando uma mazela do serviço municipal de saúde: "o posto de saúde tá fechado há muito tempo, tem um consultório dentário fechado lá dentro, que nunca foi usado" (A, 42, São Lourenço). Os agentes de saúde visitam as casas quase que exclusivamente para fazer entrega de medicamentos que são prescritos, na maioria das vezes, por um médico clínico geral. Percebe-se que, nesse caso, o incremento das receitas municipais advindas da mineração não reverte em melhora na qualidade dos serviços oferecidos à população, sobretudo, conforme objeto de estudo deste trabalho, no que diz respeito à saúde coletiva. 
Essa percepção corrobora aspectos identificados em outros trabalhos, como o não reconhecimento e a não atenção a questões que envolvem a vida e a saúde dessa parcela da população (RIQUINHO, 2009).

É comum na literatura da ecologia política atual, sobretudo em trabalhos de investigação sobre mineração, a existência de conflitos ambientais resultantes do processo de incompatibilidade existente entre os interesses da grande empresa e os da população local. No caso da mineração em Itamarati de Minas, a partir dos relatos das famílias, percebe-se a ocorrência de conflitos de forma mais velada. Não existe uma organização que defenda os direitos dos agricultores. As negociações com a empresa para a venda dos direitos de exploração é realizada de forma individual. Essa estratégia fragiliza as iniciativas de organização horizontal por parte das famílias, o que poderia garantir, por exemplo, compensações justas ou participação nos lucros da produção. Dessa forma, os relatos de conflitos são pontuais, entre aqueles que resolvem, usando uma expressão local, "bater de frente com a empresa" (A, 41). Essa pontualidade, por sua vez, não pode ser confundida com leniência da população com o processo de mineração. A maior parte das famílias entrevistadas relata denúncias e insatisfação, indicando situações de atrito com a empresa. São delatados casos de acordos, "promessas" (A, 78) não cumpridas pela empresa, pactuados durante o processo de negociação de compra da bauxita; fechamento da via principal de escoamento do minério por um agricultor devido à poeira: "coloquei pneus, arame e madeira na estrada para impedir os caminhões de passar, cansei de pedir para jogarem água na estrada" (A, 49); e até casos de ameaças, como o de uma agricultora que "depois de ligar várias vezes para a empresa, de fazer um boletim de ocorrência policial e de colocar faixas pedindo a diminuição da poeira, resolvi fechar a estrada; e nesse dia cheguei a ser ameaçada por um motorista de caminhão" (Aa, 53). Portanto, seria incorreto considerar a não existência de conflitos, muito embora a região careça de movimentos organizados de forma horizontal e articulados que lutem pela defesa e pelos direitos da agricultura familiar.

\section{Discussão}

Conforme apresentado, nas áreas rurais de Itamarati de Minas predominam modelos econômicos ligados à agricultura familiar. Esse tipo de agricultura é responsável pela sobrevivência de parte importante da população do município. Essas famílias 
possuem uma forma de valoração do ambiente no qual estão inseridas, diferenciada dos valores atribuídos pela empresa. O território, para as famílias de agricultores, é mais que um espaço de moradia, mas também de sobrevivência econômica e reprodução social. Portanto, essa coletividade é a que sofre diretamente e de forma mais aguda os impactos do processo de mineração de bauxita.

Quanto aos processos produtivos como o da mineração, a ocorrência dos riscos potencializa junto à população, conforme Habermann e Gouveia (2008, p. 1106), a produção de "stress, agravos, doenças, morte, danos à propriedade, perda econômica e ainda implicações ao meio ambiente, com perda de flora e fauna, poluição e desequilíbrio ambiental". Como contextos vulneráveis, consideram-se aqueles onde

[...] os riscos dos sistemas-técnico-ambientais [neste caso, a indústria da mineração] são agravados em decorrência de vulnerabilidades sociais que permitem a (re)produção social das populaçôes, setores produtivos e territórios vulneráveis aos riscos [em que] os processos decisórios e as instituiçōes responsáveis pela sua regulação e controle não atuam de forma efetiva, pelo menos para certos e grupos e territórios (PORTO, 2007, p. 35).

Evidentemente, essas novas formas de vulnerabilidade, introduzidas nos territórios de forma desigual, como no caso da mineração, se pronunciam também de forma desigual entre os diversos segmentos sociais (RIGOTO; AUGUSTO, 2007). Essa desigualdade fica exposta e latente, tanto nos danos ambientais quanto nos agravos à saúde da população rural do município de Itamarati de Minas, surgidas a partir do desenvolvimento do processo de mineração.

Para Acselrad, Mello e Bezerra (2009, p. 15), a noção de injustiça ambiental se alicerça na "concentração dos benefícios do desenvolvimento nas mãos de poucos, bem como a destinação desproporcional dos riscos ambientais para os mais pobres". A indústria da mineração no município de Itamarati de Minas não redistribui riqueza no território onde a mesma atua. Do mesmo modo, a aferição da riqueza, por parte da empresa, se processa de mãos dadas com a produção de danos ambientais que, ao serem externalizados, redimensionam as situações de riscos e de sobrevivência da população. A redução e a poluição das águas, das áreas de plantio e a poeira produzida são exemplos de situações de injustiça ambiental vivenciada pelas famílias locais.

O modelo de valoração das comunidades de agricultores se distingue daquele próprio das formas predominantes do grande capital. Nesse sentido, conforme 
assinalado por Carpintero e Naredo (2003), a civilização industrial usa uma racionalidade de valores monetários, destacando a dimensão da criatividade para fazer bens de valor e utilidade, mantendo os olhos cerrados para os danos ao meio ambiente. $\mathrm{O}$ ambiente é circunscrito ao campo dos valores monetários como fonte de recursos naturais que carecem de ser avaliados. São contabilizados os custos da extração e do manejo, excluindo das contas sua substituição ou reposição, caminhando de forma célere para sua deterioração. Esse modelo, segundo Carpintero e Naredo (2003, p. 10), privilegia “las desigualdades sociales y territoriales a través de esa abstracción social que es el dinero y sus ramificaciones financeiras". Essa valoração da natureza por parte do grande capital, representado em Itamarati de Minas pela empresa mineradora, revela uma dicotomia em relação aos anseios e necessidades da população tradicional que ocupa esses territórios. Para as famílias, o território possui valores que transcendem sua simples monetarização; os valores considerados dizem respeito a sobrevivência e reprodução social, que são garantidas pelas formas chamadas de tradicionais de ocupação do território menos impactantes ao ambiente, caracterizadas pela maior sustentabilidade. Princípios que estão alinhavados aos conceitos da promoção da saúde, associados a valores como os de "vida, saúde, solidariedade, equidade, democracia, cidadania, desenvolvimento, participação, dentre outros” (HAESER, BÜCHELE; BRZOZOWSKI, 2012).

A agricultura familiar do município de Itamarati de Minas padece da inserção vertical de seu território na lógica global de acumulação capitalista. Desta feita, o território se transforma, com o objetivo maior de atender às demandas e necessidades de cadeias produtivas cujo centro se encontra distante (a bauxita é transformada em alumínio na cidade de Alumínio, no estado de São Paulo e de lá parte da produção é exportada). A inserção da qual o município de Itamarati de Minas vem participando a partir do incremento da mineração pode ser caracterizada como produto do estágio atual do capitalismo globalizado, no qual a exploração de recursos naturais nos países periféricos ganhou novos contornos. Essa forma de acumulação, batizada por Harvey (2010) de "pilhagem", se sustenta não apenas mediante a extração da mais-valia e dos tradicionais mecanismos de mercado, mas também mediante práticas predatórias, que se aplicam aproveitando-se das desigualdades para pilhar diretamente os recursos de países e regiōes mais frágeis, como no caso do município de Itamarati de Minas. 
Nessa mesma linha de raciocínio Breilh (2008, p. 162) chama de "inacreditáveis atrevimentos" e depredação radical, a procura pela legitimidade do grande capital, que é forjada a partir de mínimas concessões de pacotes de assistência social, tendo o poder estatal se transformado em um "instrumento direto dessa acumulação violenta”. Em Itamarati de Minas, essas concessões tomam forma na manutenção de uma organização não governamental (ONG) que presta serviços a crianças; à promoção de cursos de educação ambiental, também para crianças; à prestação de benefícios a alguns produtores rurais, como empréstimo de máquinas para construção e/ou reformas de estradas; à indenização aos proprietários das propriedades mineradas (com valores questionáveis); ao bom convívio com as autoridades estabelecidas que, conjuntamente com a produção dos royalties, garante a adesão e o apoio, quase que irrestrito, da estrutura administrativa municipal aos interesses da empresa.

Fazendo uso do referencial emprestado pela Ecologia Política, cabe compreender que o processo de vulnerabilização e de produção de cenários de injustiça ambiental, que comprometem a saúde coletiva no território do município de Itamarati de Minas, se articula aos modelos globais de produção. Segundo Acselrad (2010, p. 34), a existência de uma "nova geopolítica mundial dos recursos naturais" contribui para explicar o incremento dos conflitos ambientais nos países da América Latina. Nesse cenário, as mercadorias que esses países colocam no mercado internacional dependem direta ou indiretamente de energia, água, minérios, nível de insolação e espaço territorial. Por sua vez, o acesso a esses recursos são a mola que impulsiona a escolha dos locais de investimentos no continente. Os conflitos ambientais surgem exatamente a partir do avanço da fronteira de exploração desses recursos e dos frequentes choques com sujeitos sociais localizados, dispostos, conforme Acselrad (2010, p. 34), "a dar outros sentidos a seus territórios, atribuir outros destinos a seus recursos comunais, optar por outros modos de regular o tempo-espaço aos quais, muitas vezes, associam suas próprias identidades". A mineração ocorre em um território onde os usos de recursos, como a água, é compartilhado por todos e o valor desses recursos não pode ser mensurado de forma meramente monetária.

Nesse processo conflituoso entre as formas de produção e valoração do território, riscos tecnológicos ambientais são gerados, do mesmo modo que a degradação ambiental e os agravos à saúde que são produzidos afetam de forma 
desigual o espaço e a população que o ocupa. Entre as externalidades produzidas durante o processo de mineração, importante destaque, realçado nas entrevistas, deve ser dado aos danos à saúde da população e às formas de economia tradicional. A poeira excessiva produz agravos à saúde da população, criando uma dupla vulnerabilização: afeta a saúde e a qualidade de vida das famílias que vivem na região onde ocorre a exploração da bauxita; e afeta, na mesma intensidade, as formas produtivas que garantem a sobrevivência e reprodução social coletiva. Vale considerar, também, que parte do conjunto de externalidades produzidos no processo de mineração de bauxita se associa à diminuição da autonomia dos agricultores. Ao afetar as formas tradicionais de produção e de sobrevivência, os agricultores acabam sendo tolhidos de sobreviver com seus próprios meios, a partir de suas próprias propriedades.

A diminuição ou escassez de água pode significar o fim das formas tradicionais de produção, ligadas ao plantio e a criação de animais. Muito embora a ocorrência de conflitos entre a população e a empresa seja pontual, não se pode desconsiderar sua existência e importância. De forma distinta de outros empreendimentos, ligados à mineração na Amazônia (LEROY, 2010; SEVÁ FILHO, 2010; ACSELRAD 2004; BECKER, 2007), ou em outras regiões, como no próprio estado de Minas Gerais (ZHOURI; OLIVEIRA, 2005;), na região de Itamarati de Minas os conflitos não chegaram, ao menos até o momento, a ganhar uma forma mais robusta e orgânica. Talvez a inexistência de grupos já organizados como quilombolas ou articulados ao Movimento dos Atingidos pelas Barragens (MAB), ou mesmo de sindicatos agrícolas mais atuantes possa oferecer pistas sobre a ausência dessa organização no território de Itamarati de Minas.

\section{Considerações finais}

O presente trabalho procurou compreender os impactos ao ambiente e à saúde coletiva resultantes do processo de mineração de bauxita no município de Itamarati de Minas. Os impactos ambientais são difusos, como a poeira e a redução das águas, e afetam a saúde e as formas de sobrevivência tradicional da população local, baseada na pequena agricultura e pecuária.

Os danos ambientais devem ser percebidos como externalidades geradas pelo processo produtivo que credita apenas valores monetários ao meio ambiente, monopoliza os ganhos e democratiza os impactos ambientais. A lógica da 
empresa, representante do grande capital, é diferente da lógica da população local: enquanto que para a empresa a busca pelo lucro intensifica a produção de danos ao ambiente, a população local tem, nesse território, um espaço de sobrevivência e de reprodução social.

As externalidades produzidas pela mineração criam situações que vulnerabilizam as populaçôes que ocupam o território. Os cenários de vulnerabilidade incluem danos ao ambiente que afetam a sobrevivência econômica e danos à saúde coletiva da população. Produz-se, dessa forma, um contexto de injustiça ambiental: os danos ambientais destinam às famílias um fardo desproporcional de impactos que afetam de forma direta a saúde coletiva e as formas de sobrevivência dessa população.

Destarte, fica patente a necessidade de se repensar as formas de desenvolvimento dos territórios de modo a garantir, para as populaçóes tradicionais que historicamente ocupam esses territórios, aquilo que Porto e Finamore (2012, p.1494), chamam de "protagonismo na produção de conhecimentos". Esse protagonismo poderia ser alcançado a partir de iniciativas populares e participativas (RUIZ; GERHARDT, 2012) em que possam ser valorizadas as virtudes do território em questão, tais como a criação de associações familiares de produtores como os de café, frutas e/ou horticultura; uma opção válida, aproveitando-se das características favoráveis do solo e do clima.

Um possível incremento da produção agrícola nesses moldes poderia fortalecer os laços de solidariedade entre as famílias, caminhando para uma forma de economia também solidária e ao abastecimento da própria municipalidade. Para tanto, torna-se iminente a necessidade de ampliar a participação de forma democrática das populações nas discussões sobre o desenvolvimento local. É preciso garantir às populações "assumirem-se como sujeitos - e não simples objetos - da própria realidade que vivenciam, o que inclui a disputa por valores" (PORTO; FINAMORE, 2012, p. 1.497), como decidir sobre o destino de seus territórios. ${ }^{4}$

\section{Referências}

ASSOCIAÇÃO BRASILEIRA DE ALUMÍNIO. Disponível em: <http://www.abal.org. br/estatisticas/nacionais/> Acesso em: 19 fev. 2014.

ANTUNES, R. O continente do Labor. São Paulo: Boitempo, 2011.

ACSELRAD, H. Ambientalização das lutas sociais - o caso do movimento por justiça ambiental. Estudos Avançados. São Paulo, v. 24, n. 68, p. 103-119, 2010. 
ACSELRAD, H.; MELLO, C. C. A.; BEZERRA, G. N. O que é Justiça Ambiental? Rio de Janeiro: Garamond, 2009.

ACSELRAD, H. (Org.). A Re-volta da Ecologia Politica: conflitos ambientais no Brasil. Rio de Janeiro: Relumé Dumará, 2004.

BECKER, B. K. Amazônia: geopolítica na virada do III milênio. Rio de Janeiro: Garamond, 2007.

BRANDĀO, C. Território \& Desenvolvimento: as múltiplas escalas entre o local e o global. Campinas: Editora da Unicamp, 2007.

BRASIL. Ministério da Saúde. Conselho Nacional de Saúde. Resolução no. 196, de 10 de outubro de 1996. Diretrizes e Normas Regulamentadoras de Pesquisas Envolvendo Seres Humanos. Diário Oficial da União, 16 out. 1996.

BREILH, J. Pilhagens, Ecossistemas e Saúde, p. 159-180. In: MIRANDA, A. et al. Território, Ambiente e Saúde. Rio de Janeiro: Editora Fiocruz, 2008.

CARPINTERO, O.; NAREDO, J. M. La Ecología Industrial. Economia Industrial. Madrid, n. 351, p.10-14, 2003.

COElHO, M. C. N.; CUNHA, L. H.; WANDERlEY, L. J. M. Conflitos em áreas de mineração na Amazônia: Os casos dos quilombolas e dos moradores de beiras de lagos, dos canais fluviais e de estradas em Oriximiná, p. 276-300. In: ZHOURI, A.; LASCHEFSKI, K. (Org.). Desenvolvimento e conflitos ambientais. Belo Horizonte: Editora da UFMG, 2010. DATASUS. Banco de dados do Sistema Único de Saúde. Disponível em: <http://www2. datasus.gov.br/DATASUS/index.php?area=0206>. Acesso em: 05 abr. 2013.

FUNDAÇÃO JOÃO PINHEIRO. <Disponível em www.fjp.mg.gov.br>. Acesso em: 01 abr. 2013.

LEROY, J. P. Amazônia: território do capital e territórios dos povos, p. 92-113. In: ZHOURI, A.; LASCHEFSKI, K (Org.). Desenvolvimento e conflitos ambientais. Belo Horizonte: Editora da UFMG, 2010.

HABERMANN, M.; GOUVEIA, M. Justiça Ambiental: uma abordagem ecossocial em saúde. Revista de Saúde Pública. São Paulo, v. 42, n.11, p.1105-1111, 2008.

HAESER, L. M.; BÜCHELE, F.; BRZOZOWSKI, F. S. Considerações sobre a autonomia e a promoção da saúde. Physis Revista de Saúde Coletiva. Rio de Janeiro, v. 22 n.2, p. 605620, 2012.

HARVEY, D. The Enigma of Capital: and the crisis of Capitalism. London: Profile Books, 2010.

HARVEY, D. O Novo Imperialismo. São Paulo: Loyola, 2005.

HENRIQUES, A. B; PORTO, M. F. S. A insustentável leveza do alumínio: impactos socioambientais da inserção do Brasil no mercado mundial de alumínio primário. Ciência \& Saúde Coletiva. Rio de Janeiro, v. 18, n. 11, p. 3223-3234, 2013 a. 
HENRIQUES, A. B; PORTO, M. F. S. Território, ecologia política e justiça ambiental: o caso da produção de alumínio no Brasil. E-cadernos CES. Coimbra, n. 17, p. 31-55, 2013b. INSTITUTO BRASILEIRO DE GEOGRAFIA E ESTATÍSTICA. Censo Agropecuário de 2006. Disponível em: <http://www.ibge.gov.br/home/estatistica/economia/agropecuaria/ censoagro/>. Acesso em: 25 mar. 2013.

. Censo de 2010. Disponível em: <http://censo2010.ibge.gov.br/resultados.html>. Acesso em: 01 abr. 2013.

PORTO, M. F. S.; FINAMORE, R. Riscos, saúde e justiça ambiental: o protagonismo das populações atingidas na produção de conhecimento. Ciência \& Saúde Coletiva. Rio de Janeiro, n. 17, v. 6, p. 1493-1501, 2012.

PORTO, M. F. S. Uma Ecologia Politica dos Riscos: principios para integrarmos o local e o global na promoção da saúde e da justiça ambiental. Rio de Janeiro: Editora da Fiocruz, 2007. RIGOTO, R. M.; AUGUSTO, L. G. S. Saúde e ambiente no Brasil: desenvolvimento, território e iniquidade social. Cadernos de Saúde Pública. Rio de Janeiro, 23 sup., n. 4, p.475-501, 2007.

RIQUINHO, D. L. A outra face dos determinantes sociais de saúde: subjetividades na construção do cotidiano individual e coletivo em uma comunidade rural. 2009. 212 f. Dissertação (Mestrado em Enfermagem) - Escola de Enfermagem, Universidade Federal do Rio Grande do Sul, Porto Alegre, 2009.

RUIZ, E. N. F.; GERHARDT, T. E. G. Políticas públicas no meio rural: visibilidade e participação social como perspectivas de cidadania solidária e saúde. Physis Revista de Saúde Coletiva. Rio de Janeiro, n. 22, v. 3, p. 1191-1209, 2012.

SEVÁ FILHO, A. O. Problemas intrínsecos e graves da expansão mineral, metalúrgica, petrolífera e hidrelétricas nas Amazonas, p. 114- 147. In: ZOHURI, A.; LASCHEFSKI, K. (Org.). Desenvolvimento e conflitos ambientais. Belo Horizonte: Editora da UFMG, 2010.

SILVA, A. V. R. O município de Cataguases. Cataguases: Imprensa Oficial, 1908.

VALVERDE, O. Estudo Regional da Zona da Mata, Minas Gerais. Revista Brasileira de Geografia. Rio de Janeiro, v. 1, 1958, p. 3-82.

VOTORANTIM METAIS. Disponível em http://www.vmetais.com.br/pt-BR/Paginas/ default.aspx http://www.vmetais.com.br/pt-BR/Paginas/default.aspx>. Acesso em: 01 abr. 2013. ZHOURI, A.; LASCHEFSKI, K. Desenvolvimento e conflitos ambientais: um novo campo de investigação, p. 11-31. In: ZOHURI, A.; LASCHEFSKI, K. (Org.). Desenvolvimento e conflitos ambientais. Belo Horizonte: Editora da UFMG, 2010.

ZHOURI, A.; OLIVEIRA, R. Paisagens industriais e desterritorialização de populações locais: o caso das hidrelétricas em Minas Gerais. In: ZHOURI, A.; LASCHEFSKI, K.; PEREIRA, D. (Org.). A insustentável leveza da política ambiental: desenvolvimento e conflitos socioambientais. Belo Horizonte: Autêntica, 2005. 
${ }^{1}$ Tradicional, neste texto, refere-se ao modelo de produção rural característico da agricultura familiar baseado na pequena propriedade e em relaçôes de trabalho não assalariadas.

2 Matéria publicada no sítio www.megaminas.com.br alusiva à reportagem veiculada no dia 13/12/2012, sobre o avanço do produto interno bruto no município de Itamarati de Minas. A matéria foi embasada na divulgação, pelo IBGE, dos números do PIB dos municípios brasileiros no ano de 2010. Disponível em: <http://g1.globo.com/videos/minas-gerais/triangulo-mineiro/mgtv-2edicao/t/ triangulomineiro/v/itamarati-de-minas-mg-e-a-segunda-cidade-do-brasil-que-mais-subiu-no-ranking-do-pib/2293360/> Acesso em: 14 dez. 2012.

${ }^{3}$ Número de vezes que a renda do quinto superior da distribuição da renda ( $20 \%$ mais ricos) é maior do que a renda do quinto inferior ( $20 \%$ mais pobres) na população residente em determinado espaço geográfico, no ano considerado.

${ }^{4}$ A. B. Henriques foi responsável pela concepção do presente artigo, tendo realizado a pesquisa de campo e a redação do texto. M. F. de S. Porto contribuiu na redação e na correção da versão final do texto. 


\section{Abstract}

Mining, family agriculture and collective health: a case study in the region of Itamarati de Minas-MG, Brazil

This paper discusses, in the light of the paradigms of political ecology and environmental justice, social, environmental and public health impacts resulting from the mining process in the city of Itamarati de Minas-MG, Brazil. The objectives are understanding risks and social and environmental vulnerability, as well as the seizure of conflicts and environmental injustice scenarios in this economic activity. The first part briefly presents some features of the current model of mineral exploration and subordinate worldwide integration of territories such as the municipality of Itamarati de Minas. Then there is a description of the study area and the sources and methods used at work; then the results of the interviews are presented. It was noticed that the bauxite mining process is impacting the environment and the community ways of life; likewise, it acts negatively in the health production process and disease, damaging a health promotion situation.

> Key words: collective health; environmental health; mining; environmental justice. 